\title{
Correlation between Periodontal Disease and Oral Health Related Quality of Life
}

\section{Sadia Rashid, Sana Zafar, Ayma Syed, Danish Javed, Nadia Junaid, Muhammad Umair Dastgir Bhatti* and Muhammad Rizwan}

Department of Community and Preventive Dentistry, Foundation University Islamabad, Pakistan

*Corresponding Author: Muhammad Umair Dastgir Bhatti, Department of Community and Preventive Dentistry, Foundation University Islamabad, Pakistan.
Received: August 17, 2020

Published: September 16, 2020

(C) All rights are reserved by Muhammad

Umair Dastgir Bhatti., et al.

\section{Abstract}

The objective of the study was to assess the correlation between periodontal disease and oral health related quality of life amongst study sample. It was a case control study including 632 individuals screened by calibrated examiners at Department of Oral Diagnosis, Dental Hospital, Sialkot, Pakistan. Oral examination was carried out by two calibrated examiners to measure the periodontal disease i.e. (CAL more than $2 \mathrm{~mm}$, BOP more than 6 sites and PPD more than $4 \mathrm{~mm}$ ). Three hundred and sixteen (316) were participants with periodontal disease (case group) and 316 were participants without periodontal disease (control group). A back translated Urdu version of the standardized validated oral health impact profile (OHIP-14) questionnaire was used to quantifying the impact on quality of life in both groups. Approximately $63.0 \%$ participants in case group had trouble in pronouncing words due to periodontal disease and only $9.0 \%$ in control group reported this issue. $83 \%$ participants had painful itching in mouth in the case group and $13 \%$ in control group. Majority (81.5\%) of the participants in case group were uncomfortable in eating food and $72.9 \%$ felt tense due to periodontal disease. $69.7 \%$ participants in case group were found irritable with other people as compared to only $5 \%$ in control group.

Periodontal disease showed a significant correlation with oral health related quality of life amongst the study population.

Keywords: Periodontal Disease; Oral Health Related Quality of Life; Bleeding on Probing; Probing Pocket Depth; Clinical Attachment Level

\section{Introduction}

According to the American Academy of Periodontology, Periodontal disease (PD) is "the inflammation and infection of the gums and bone that surround and support the teeth" [1]. Gingivitis and periodontitis are the two basic forms of $\mathrm{PD}$ and each has a variety of forms. Gingivitis is the inflammation of the gingival tissue; it is limited to the epithelium and gingival connective tissue. Gingivitis is painless and often unrecognized until a dental professional emphasizes its importance. Improved daily oral hygiene practices will reverse gingivitis. Periodontitis means inflammation of the supporting tissues of the teeth it is the extension of the inflammatory process from the gingiva into the connective tissue and alveolar bone supporting teeth [2]. The progression of periodontitis involves the destruction of connective tissue attachment at the most apical portion of a periodontal pocket.

The worldwide prevalence of periodontal disease is $5-20 \%$ in the adult population and is one of the leading oral health issues of the globe [3].
Clinical parameters such as bleeding on probing (BOP), probing pocket depth (PPD), and clinical attachment level (CAL) have been used to document periodontal disease. However, there are other symptoms which are non-clinical in nature but are highly relevant from the patients' point of view and often have a considerable adverse impact on their daily quality of life (QOL). The Oral Health Impact Profile (OHIP-14) is a widely used index for the measurement of oral health on the quality of life in patients with oral diseases [4]. This index is a good indicator of individual perceptions and feelings of their own oral health and their expectations regarding dental treatment and services [5].

Significant association between oral health and quality of life has been reported globally, most frequently through physical influences rather than social or psychological [6]. Literature search on association of oral health and quality of life in Pakistan only reveals one study by Bhatti., et al. [7], which explored the relationship between oral health and quality of life amongst school children of Pakistan. Periodontal disease has been associated in oral health 
related quality of life in various countries [8,9]. However, this relationship not been explored in Pakistan yet. This study aims to assess the correlation between periodontal disease and oral health related quality of life among participants visiting department of oral diagnosis, dental hospital Sialkot.

\section{Methodology}

This study followed a case control design. A total of 632 individuals were randomly selected on first come first serve basis at the Department of Oral Diagnosis, Dental hospital in Sialkot.

Inclusion criteria: All reporting individuals who were above 30 - 74 years of age, with atleast 20 teeth intact including first molars were made part of the study after consent (to participate in study and allow publication without identity being revealed). Two calibrated examiners performed the oral examination to documents the three parameters of periodontal disease i.e. Clinical attachment loss (CAL), Bleeding on probing (BOP) and Periodontal pocket depth (PPD) for all teeth present in mouth excluding third molars. Bleeding on probing, periodontal pocket depth and clinical attachment loss were measured at six sites of each tooth with a UNC-12 periowise probe by the two calibrated examiners. All 316 participants with CAL $>2 \mathrm{~mm}, \mathrm{PPD}>4 \mathrm{~mm}$ or BOP at more than 6 sites were classified as cases [10] and remaining (316) participants were classified as controls. The charting form used is attached as annex II.

A back translated Urdu version of the standardized validated oral health impact profile (OHIP-14) questionnaire (annex 1) was used to quantifying the impacts on quality of life in both groups.

Sample size was calculated using the formula [11]:

\section{$n=\underline{t^{2} \times p(1-p)}$}

$\mathrm{m}^{2}$

\section{Description:}

$\mathrm{n}=$ Required sample size.

$\mathrm{t}=$ Confidence level at 95\% (standard value of 1.96).

$\mathrm{p}=$ Estimated prevalence of malnutrition in the project area.

$\mathrm{m}=$ Margin of error at 5\% (standard value of 0.05 ).

The questionnaire was translated into national language Urdu to facilitate the study subjects. Back translation was done to increase the internal validity of the study. The examiners did the piloting for the study by administering the Urdu version of questionnaire to 20 patients before the actual study. It was found that the questionnaire was easy to understand and could be completed without difficulty.

Data was analyzed through SPSS (Statistical Package for Social Sciences) version 21.0. The responses to questions were coded as numeric in order to facilitate the data entry in same software. Data was then recorded in order to carry out analysis. Responses related to the questions of four dimensions (oral symptoms, functional limitation, emotional well being and social well being) of measuring impacts of periodontal disease on quality of life were recoded i.e. never and sometimes (as fewer impacts), everyday and almost every day (as more impacts).

Analysis was done to compare the case and control groups. For categorical variables K-test of proportions (Marascuilo procedure for intergroup differences) was used. Value of $p<0.05$ was considered as level of significance.

\section{Results}

\begin{tabular}{|c|c|c|c|c|c|}
\hline \multirow{2}{*}{$\begin{array}{l}\text { Questions regarding Oral Health related } \\
\text { Qol (OHIP-14) }\end{array}$} & \multicolumn{2}{|c|}{ Cases n (\%) } & \multicolumn{2}{|c|}{ Controls n (\%) } & \multirow{2}{*}{$\begin{array}{l}\text { Significance } \\
\text { (P value) }\end{array}$} \\
\hline & Fewer Impacts & More impacts & Fewer impacts & More impacts & \\
\hline Q1. Trouble pronouncing words & $117(36.9 \%)$ & $199(63.1 \%)$ & $287(91 \%)$ & $29(9 \%)$ & $>0.001$ \\
\hline Q2. Feeling that sense of taste has worsened & $180(57 \%)$ & $136(43 \%)$ & $275(87 \%)$ & $41(13 \%)$ & $>0.05$ \\
\hline Q3. Painful itching in mouth & $54(17 \%)$ & $262(83 \%)$ & $275(87 \%)$ & $41(13 \%)$ & $>0.001$ \\
\hline Q4. Uncomfortable to eat food & $58(18.5 \%)$ & $258(81.5 \%)$ & $205(65 \%)$ & $111(35 \%)$ & $>0.001$ \\
\hline Q5. Feeling self -conscious & $246(78 \%)$ & $70(22 \%)$ & $260(82 \%)$ & $56(18 \%)$ & $<0.1$ \\
\hline Q6. Feeling tense & $86(17.1 \%)$ & $230(72.9 \%)$ & $240(76 \%)$ & $76(24 \%)$ & $>0.001$ \\
\hline Q7. Diet has been unsatisfactory & $104(33 \%)$ & $212(67 \%)$ & $177(56 \%)$ & $139(44 \%)$ & $<0.1$ \\
\hline Q8. Interruption in meals & $218(69 \%)$ & $31 \%(98)$ & $237(75 \%)$ & $79(25 \%)$ & $<0.1$ \\
\hline Q9. Difficulty to relax & $281(89 \%)$ & $35(11 \%)$ & $294(93 \%)$ & $22(7 \%)$ & $<0.1$ \\
\hline Q10. Feeling Embarrassing & $250(79 \%)$ & $66(21 \%)$ & $256(81 \%)$ & $60(19 \%)$ & $<0.1$ \\
\hline Q11. Irritability with other people & $99(31.3 \%)$ & $217(69.7 \%)$ & $300(95 \%)$ & $16(5 \%)$ & $>0.001$ \\
\hline Q12. Difficulty in doing usual job & $145(46 \%)$ & $171(54 \%)$ & $180(57 \%)$ & $36(43 \%)$ & $<0.1$ \\
\hline Q13. Less satisfying life & $164(52 \%)$ & $152(48 \%)$ & $221(70 \%)$ & $95(30 \%)$ & $<0.1$ \\
\hline Q14. Totally unable to function & $123(39 \%)$ & $193(61 \%)$ & $256(81 \%)$ & $60(19 \%)$ & $>0.05$ \\
\hline
\end{tabular}

Table 1: Correlation between periodontal disease and OHRQOL. 


\section{Discussion}

This study aims to assess the correlation between periodontal disease and oral health related quality of life among participants visiting department of oral diagnosis, dental hospital Sialkot.

The results of the study confirm that PD has significant correlation oral health related quality of life of study population. This finding is similar to previous study conducted in Sweden [12] that also proved that there is considerable effect of PD on quality of life.

Study revealed that $63.1 \%$ participants in case group had difficulty in pronouncing words as compared to only $9 \%$ in control group. The results of case group are different from the study conducted in Jordan [13] where only $6.7 \%$ people had difficulty in pronouncing words. However, the results from Jordan are similar to our control group results where only $9 \%$ people have reported trouble in pronouncing words. This is an indicator that periodontal disease has a strong correlation to oral health related quality of life and affects it adversely.

It is evident from current study that $43 \%$ participants in case group felt that sense of taste had worsened and only $13 \%$ from control group felt the same. The results of the study carried out in Romania [14] reported that only 5.0\% patients believed that their sense of taste had worsened. This is similar to findings of our control group participants but different from case group.

It is important to mention that $83 \%$ patients in case group had itching in mouth which affected their oral health related quality of life. The results of our study are much closer to the study from Jordan [13], which reported that $70.7 \%$ patients had painful itching in mouth.

Study identified that a major proportion (81.5\%) of participants was uncomfortable in eating food due to periodontal disease in case group. The findings of our study are almost comparable with the study in Jordan [13] which confirmed that majority (64.2\%) of patients were uncomfortable in eating food due to periodontal disease.

In the present study (case group), almost $73 \%$ patients felt tense and almost $70 \%$ patients were found irritable with other people that eventually affected their quality of life. While study in Oman [15] confirmed in their study that $61.0 \%$ patients felt tense followed by $51.7 \%$ irritable with other people due to periodontal disease.
Another study conducted in Santo Dominigo [16], confirmed that the main problems associated with patients having CAL more than $2 \mathrm{~mm}$ were physical pain (73\%), psychological disability (66\%) and physical disability (64\%). These findings are similar to case group of our study where $83 \%$ reported physical pain (painful itching), 73\% psychological disability (feeling tense, uncomfortable eating food) and 61\% physical disability (totally unable to function).

The study could not establish any statistically significant difference between case group and control group concerning the oral health related quality of life questions related to feeling of selfconscious, diet being unsatisfactory, interruptions in meals, difficulty to relax, feeling embarrassing, difficulty in doing usual jobs and less satisfying life. These variables need further exploration in future studies. It is also recommended, that health education programs be held at community level to educate people about oral health and to prevent them from periodontal disease.

\section{Conclusion}

Periodontal disease interferes with oral health related quality of life among patients in numerous ways including the physical aspect, appearance, masticatory function and interpersonal relationships. Present study found a strong correlation between periodontal disease and oral health related quality of life among study individuals who had trouble in pronouncing words, complained that their sense of taste has worsened while majority had painful itching in mouth. Periodontal disease is preventable and appropriate health education programs and strategies can help reduce the disease, which can lead to a better quality of life amongst population.

\section{Annex I}

OHIP 14 questionnaire

In the past 4 months because of my gums/teeth, have I (Table 2)

\section{Annex II}

\section{Patient charting form}

Patient Name

Age Gender M/ F

Marital Status Medical History/

Habits

\section{(Figure)}


Correlation between Periodontal Disease and Oral Health Related Quality of Life

\begin{tabular}{|c|c|c|c|c|}
\hline Question & Never & Sometimes & Often & Everyday/Almost Everyday \\
\hline $\begin{array}{l}\text { Functional limitation } \\
\text { Q1. Had trouble pronouncing words. }\end{array}$ & & & & \\
\hline Q2. Felt that sense of taste had worsen. & & & & \\
\hline $\begin{array}{l}\text { Physical Pain } \\
\text { Q3. Had Painful itching in mouth. }\end{array}$ & & & & \\
\hline Q4. Was uncomfortable eating food. & & & & \\
\hline $\begin{array}{l}\text { Psychological discomfort } \\
\text { Q.5. Has been feeling self conscious. }\end{array}$ & & & & \\
\hline Q6. Has felt tense. & & & & \\
\hline $\begin{array}{l}\text { Physical disability } \\
\text { Q7. Diet has been unsatisfactory. }\end{array}$ & & & & \\
\hline Q8. Has had to interrupt meals. & & & & \\
\hline $\begin{array}{l}\text { Psychological disability } \\
\text { Q9. Finds it difficult to relax. }\end{array}$ & & & & \\
\hline Q10. Has been a bit emberaasee. & & & & \\
\hline $\begin{array}{l}\text { Social Disability } \\
\text { Q11. Has been irritable with other people. }\end{array}$ & & & & \\
\hline Q12. Has had difficulty doing usual jobs. & & & & \\
\hline $\begin{array}{l}\text { Handicap } \\
\text { Q13. Has found life less satisfying. }\end{array}$ & & & & \\
\hline Q14. Has been totally unable to function. & & & & \\
\hline
\end{tabular}

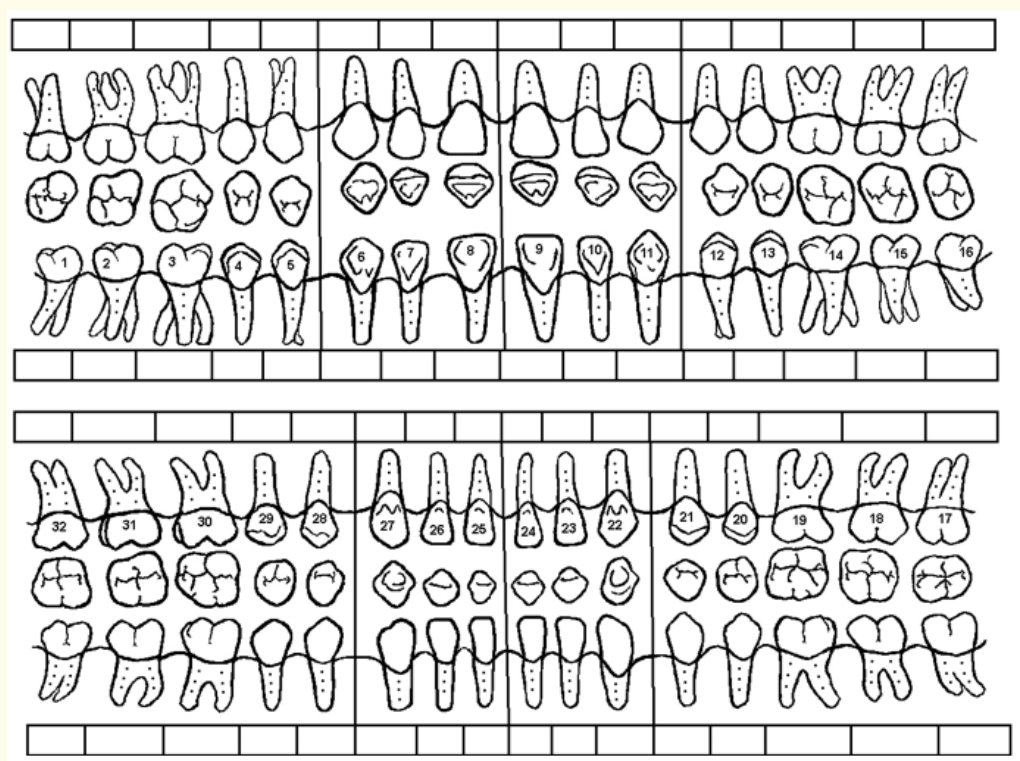

Figure 
Periodontal disease parameters

\begin{tabular}{|l|l|l|}
\hline $\begin{array}{l}\text { Bleeding on Probing } \\
\text { (BOP) }\end{array}$ & ( ) Less than 6 sites & ( ) 6 or more sites \\
\hline $\begin{array}{l}\text { Periodontal Pocket } \\
\text { Depth (PPD) }\end{array}$ & ( ) Less than $4 \mathrm{~mm}$ & ( ) $4 \mathrm{~mm}$ or above \\
\hline $\begin{array}{l}\text { Clinical Attachment } \\
\text { Loss (CAL) }\end{array}$ & ( ) Less than $2 \mathrm{~mm}$ & ( ) $2 \mathrm{~mm}$ or above \\
\hline
\end{tabular}

\section{Bibliography}

1. AAP, American Academy of Periodontology (2014).

2. Eke PI., et al. "Advances in Surveillance of Periodontitis: The Centers for Disease Control and Prevention Periodontal Disease Surveillance Project". Journal of Periodontology (2012): $1-9$.

3. World Health Organization. The World Oral Health Report. Continuous improvement of oral health in the 21st century, the approach of the WHO Global oral health program (2003).

4. Slade GD and Spencer AJ. "Development and evaluation of the Oral Health Impact Profile". Community Dental Health 11.1 (1994): 3-11.

5. Palma PV., et al. "Impact of periodontal diseases on healthrelated quality of life of users of the Brazilian unified health system". International Journal of Dentistry (2013): 150357.

6. McGrath C and Bedi R. "Measuring the impact of oral health on quality of life in Britain using OHQoL-UK(W)". Journal of Public Health Dentistry 63 (2003): 73-77.

7. Bhatti MUD., et al. "Self reported impacts of oral health on quality of Life amongst 11-14 years old school children of Lahore, Pakistan". Pakistan Oral and Dental Journal 30 (2010): 175-180.

8. Araújo AC., et al. "Impact of periodontal disease on quality of life”. QI. Quintessence International 41 (2010): e111-e118.

9. Aslund M., et al. "Measuring oral health-related quality-of-life using OHQoL-GE in periodontal patients presenting at the University of Berne, Switzerland". Oral Health and Preventive Dentistry 6 (2008): 191-197.

10. American Academy of Periodontology. World Workshop on the Classification of Periodontal and Peri-Implant Diseases and Conditions (2017).

11. World Health Organization. Sample size design (2020).
12. Jansson H., et al. "Impact of periodontal disease experience on oral health-related quality of life". Journal of Periodontology 85 (2014): 438-445.

13. Al Habashneh R., et al. "Use of the Arabic version of Oral Health Impact Profile-14 to evaluate the impact of periodontal disease on oral health-related quality of life among Jordanian adults". Journal of Oral Science 54 (2012): 113-120.

14. Murariu A and Hanganu C. "Oral health and quality of life among 45- to 64-year-old patients attending a clinic in Iasi, Romania". OHDMBSC, VIII (2009): 7-11.

15. Al-Harthi L. "The impact of periodontitis on oral-health-related quality of life among Omani teachers". Oman: University of Otago (2012).

16. Collins J., et al. "Prevalence of clinical attachment loss in adolescents in Santo Domingo, Dominican Republic". Journal of Periodontology 76 (2005): 1450-1454.

\section{Assets from publication with us}

- Prompt Acknowledgement after receiving the article

- Thorough Double blinded peer review

- Rapid Publication

- Issue of Publication Certificate

- High visibility of your Published work

Website: www.actascientific.com/

Submit Article: www.actascientific.com/submission.php

Email us: editor@actascientific.com

Contact us: +919182824667 